Journal of

Sociology

\title{
Can the subaltern heal? Medical marijuana in Aotearoa New
} Zealand

\begin{tabular}{|c|l|}
\hline Journal: & Journal of Sociology \\
\hline Manuscript ID & JOS-2019-106.R1 \\
\hline Keyword: & $\begin{array}{l}\text { Subaltern therapeutics, statist medicine, medical marijuana, cannabis } \\
\text { reform }\end{array}$ \\
\hline Abstract: & $\begin{array}{l}\text { In Aotearoa New Zealand marijuana use is illegal for recreational } \\
\text { purposes, but theoretically patients can gain access to medicinal forms of } \\
\text { marijuana if health professionals, the Ministry of Health and the relevant } \\
\text { government Minister approved. This paper uses the concepts of statist } \\
\text { medicine and subaltern therapeutics to provide insight into the debates } \\
\text { over the therapeutic use of marijuana in cases of serious or terminal } \\
\text { illness. Statist medicine's process of approval of marijuana use is } \\
\text { that safety and efficacy standards are met. Patients often reverted to } \\
\text { illegal means of accessing the plant rather than negotiate these } \\
\text { processes. The regulation of therapeutic uses of marijuana provides } \\
\text { insights into the role of statist medicine and subaltern therapeutics, } \\
\text { alerting us to the possibilities of other subaltern therapeutic practices } \\
\text { that operate beyond the gaze of the state. }\end{array}$ \\
\hline
\end{tabular}

\section{SCHOLARONE Manuscripts}




\title{
Can the subaltern heal? medical marijuana in Aotearoa New Zealand
}

\begin{abstract}
In this paper the concepts of statist medicine and subaltern therapeutics are used to provide insight into the debates over the therapeutic use of marijuana in cases of serious or terminal illness. In 2015 medical marijuana gained public attention in Aotearoa New Zealand as cases of people facing life threatening conditions who wished to use marijuana for therapeutic purposes were given voice in the popular media. In Aotearoa New Zealand marijuana use is illegal for recreational purposes, but theoretically patients with particular conditions could gain access to medicinal forms of marijuana if health professionals, the Ministry of Health and the relevant government Minister approved. This approval process is embedded within statist medicine's regulatory regimes, where access can be provided on condition that the medication meets standards of safety and efficacy. Patients faced with the difficulty of negotiating the processes of statist medicine to access medical marijuana often reverted to illegal means of accessing the plant. Access to illegal forms of marijuana for medical purposes could be through 'green fairies', people who provided the plant for therapeutic purposes in a way that was distant from the criminalised recreational use of the drug obtained through 'dealers'. The process of the state, patients and marijuana providers negotiating the regulation of therapeutic uses of marijuana provides insights into the role of statist medicine and subaltern therapeutics. The case of medical marijuana alerts us to the possibilities of other subaltern therapeutic practices that operate beyond the gaze of the state.
\end{abstract}

Keywords: New Zealand; subaltern therapeutics; statist medicine; medical marijuana; cannabis reform 


\section{Introduction}

In mid-2015 the issue of medical marijuana surged into public consciousness in Aotearoa New Zealand with the case of Alex Renton, a teenager who had suffered an extreme seizure that resulted in status epilepticus and his being kept in an induced coma (Cooke, 2015). His doctors were unable to achieve any success in treating his condition with available pharmaceutical medicines, of which more than 20 were tried over a period of around 60 days. His family then sought access to medical marijuana (Moir, 2015a). After an initial reluctance, the hospital staff became convinced there was little harm in trying the alternative treatment. Peter Dunne, then Associate Health Minister, and the Ministry of Health $(\mathrm{MOH})$ quickly approved the application for a one-off use of Elixinol, a cannabidiol (CBD) drug. Cannibidiol is a non-psychoactive drug derived from the hemp plant. The drug had to be shipped from the United States before it became available for Alex's first dose, a week after it was approved (Moir, 2015c). Rose Renton, Alex's mother, was reported to have flouted the law by covertly administering cannabis oil to her son before the Elixinol had been approved (Stuff, 2015a). Alex died a few days after the formal treatment was finally begun (Stuff, 2015b). An official report released after Alex's death concluded that the treatment had no noticeable effect on his condition but may have had some effect as a palliative (Wade, 2016). Alex's family disputed this conclusion stating that they saw improvement in both his comfort and condition when given Elixinol (Moir, 2016b).

Significant features of the struggle around access to medical marijuana (the terms marijuana and cannabis will be used interchangeably) can be discerned in this sad 
scenario. In response to human suffering people will draw on a range of therapeutic approaches, and here we see biomedicine to the fore and an alternative treatment also being sought out. The formal channels of what we term here as statist medicine must be appealed to, which means the 'alternative' treatment has to be reshaped into an acceptable form to statist medicine. Covert therapeutics, or what we will call here subaltern therapeutics, are also administered, but with the threat of the state regulatory apparatus hanging over those who take such action.

Over the ensuing months a debate over medical marijuana erupted, involving many players from different parts of the social, political and cultural spectrum of Aotearoa New Zealand. Strange new terms entered into the local lexicon, like green fairies, and new links were forged between a once forbidden drug and potentially beneficial health, economic and social effects. The case of medical marijuana brought to light a particular form of therapeutics, subaltern therapeutics. In this paper we consider the way in which medical marijuana was represented during a prominent period of public profile between mid-2015 and the end of 2017 . Through this examination it is possible to map out some of the possibilities and the limits of subaltern therapeutics.

We draw on Latourian concepts to argue that 'medical marijuana' is an unruly hybrid object. Latour argues that what he calls 'the moderns - are a type of people who maintain a belief in the existence of pure categories, such as the scientific, the economic, the political, the cultural, the local, the global' but at the same time we are surrounded by 'unruly hybrids that churn up all of culture and all of nature on a daily basis' (Blok \& Jensen, 2011, p. 55). The term 'medical marijuana' can usefully be considered as a hybrid term. It brings together the status and credibility of the 
medical complex or establishment and the deviant subculture of illicit drug consumption. The appearance of the unruly hybrid of medical marijuana required taming by established complexes, a process of re-establishing a belief in pure categories such as 'medicine', but in such taming, the term is wrestled away from subaltern therapeutics and embedded in systems of oversight and control that preserve the therapeutic status quo. The taming of medical marijuana is achieved through the extraction of specific ingredients from the plant that can be carefully controlled for dosage and potency, and that can then be put through the rigours of randomised controlled trials to determine efficacy (Grinspoon, 2018). Cannabis contains over 500 compounds and there are over 100 cannabinoids (Elsohly et al., 2016). As this process of extraction and synthesis develops the therapeutic use of marijuana continues in subaltern forms, out of public view, in an unruly manner. In the subaltern preference may be had for whole herb approaches to cannabis therapeutics, based on ideas of whole plant synergy and entourage effects that, amongst other purported benefits, can improve absorptions and reduce side effects (Ben-Shabat et al., 1998). As such we agree with the position taken by Zarhin and colleagues (2018) that medical marijuana is not an ontologically stable object, with contrasting views on the purity of a synthesised compound and the superiority of the whole plant.

We use the term complex here as a complement to the concept of statist medicine, as it includes aspects of what Bennett refers to as a medico-health complex, but there are other complexes at play in relation to the public discourses around, and control of, drug use, such as the criminal justice complex or the harm reduction complex (Bennett, 2018). These established complexes form what Bennett, drawing 
on Foucault, refers to as a dispositive, or a historically constituted orientation or approach.

The term subaltern is derived from neo-Marxist analyses of hegemony. Gramsci used the term subaltern in relation to groups or collectives who are subject to the activity of ruling groups, even in situations of resistance. For Gramsci the focus on class struggle and the contestation of hegemonic practices is not simply within the sphere of production, but can include other forms such as ecological, nationalist and religious ones (Morton, 2007). The title of this article plays on Spivak's "Can the Subaltern Speak", where Spivak suggests that subaltern sensibilities are unable to maintain any purchase as a result of the imperatives of political domination (Darder \& Griffiths, 2018).The term subaltern therapeutics has been taken up by South-Asian social science scholars to describe those everyday practices, sometimes labelled 'folk medicine', that evade and distance themselves from 'statist medicine' (Hardiman \& Mukharji, 2012). Medical marijuana as a subaltern therapeutic practice has the additional alterity of being associated with the criminal world, and as such, in an environment of criminalised production and consumption of marijuana, must remain underground, evasive and distant. However, with sufficient emphasis on the medical aspect of medical marijuana the 'object' can become incorporated into statist biomedicine. Those players who are already organised and embedded within statist medicine can take medical marijuana as an object that is shaped by their own understandings, and it is put to work to bolster their own positions. The 'object' of medical marijuana then changes according to where it is positioned. Once incorporated into statist medicine, medical marijuana is divorced from the therapeutic practices in its subaltern form, shifting control from patients and subaltern 
practitioners to medical elites. By statist medicine we are referring to both the practices of conventional medicine or biomedicine and the state regulatory apparatus in which it is embedded, including the legal requirements around diagnosis, prescription, medical claims-making, market approval and state subsidisation of medicines. Statist medicine is an outcome of a complex interplay of the interests of the medical profession to exclude therapeutic rivals, the functional needs of the state and the impact of commercial interests particularly of pharmaceutical companies, that has a long history of sociological study (see for example Anon2003; Anon 2018; Freidson, 1970; Larkin, 1983; Willis, 1983).

The use of medical marijuana appears as a subaltern practice, not tied to specific organisations or ideologies, but founded on people connected into networks where information is passed from node to node but without a visible centre. Whereas opposition could be seen from statist medicine, there did not initially appear to be any centralised space of advocacy for medical marijuana. However, such centralised agencies are possible, and these eventually made their appearance in the debate.

Aotearoa New Zealand has not followed many other states in the US and other countries in the legalisation of recreational marijuana, a phenomenon that was initiated in 2012 when the states of Colorado and Washington passed laws to legalise marijuana (Shi et al., 2019).

Between legalisation and prohibition of the use of marijuana are situations where access to medicinal cannabis is provided for certain conditions and licenses are provided for the production of cannabis for medical purposes. Such a situation has 
existed in Israel since the 1990s (Zarhin et al., 2018). In this circumstance demarcations are required to determine whether a patient is deserving or attempting to obtain cannabis for recreational purposes. In Israel, their $\mathrm{MOH}$ regulates the use of medicinal cannabis, and since 2007 it has been illegal for patients to grow cannabis. The production of cannabis for medical purposes is left to licensed commercial growers, and cannabis is only approved as a last resort for patients after other therapeutic options have failed, except for its use in treating the side effects of chemotherapy (Zarhin et al., 2018). Plans are also afoot in Israel to limit the use of medicinal cannabis to standardised product (Zarhin et al., 2018).

The focus of this paper is on medical marijuana use in relation to life threatening conditions. Pedersen and Sandberg (Pedersen \& Sandberg, 2013) examined the strategies and tactics of medical marijuana campaigners in Norway. Norwegian cannabis users also used the substance for quality of life conditions, such as for relaxation and wellbeing. Although at the time of writing, in 2013 , the Norwegian medical establishment had rejected the medicinal use of cannabis, the authors suggest that the medical cannabis movement may be having the effect of medicalising cannabis as something to be used for everyday health problems. Issues for medical doctors included their inability to accept patient knowledge as legitimate, and an inability to distance the medical use of cannabis from its recreational culture. The concerns of Norwegian medical doctors play out in similar ways in Aotearoa New Zealand, and the strictures of biomedical drug approval processes guarantee that subaltern marijuana therapeutics are re-shaped when subsumed into the narrow confines of statist medicine. 
In the USA Kilmer and MacCoun argue that the legalisation and use of medical marijuana had the effect of smoothing the way for the legalisation of non-medicinal use of marijuana. They suggest that this occurred for a number of reasons including the creation of a legalised marijuana industry and the tax potential that it offered (Kilmer \& MacCoun, 2017). It is possible that the initial bottleneck created by statist medicine's regulatory processes, which limit access to unapproved subaltern practices, would eventually be undermined in the event of full legalisation of marijuana as these unapproved practices could be taken up by alternative health practitioners, as well as folk who are not professionally trained. While this outcome may not be ideal from a state funding perspective given the lower status of alternative medicine within the statist regime, it does point to an avenue for achieving the wider goals of subaltern patients and practitioners, whose practices will not always, or may never, meet the randomised controlled trial gold standard claimed as the gateway to credibility by statist medicine.

For this paper our starting point was to systematically collate media representations of medical marijuana from June 2015 when Alex Renton's plight was first covered until the end of 2017. Material was identified using the Newztext databases, which archive most of New Zealand's daily, metropolitan and provincial newspapers, newswires, and New Zealand magazines. A range of search terms were used starting with marijuana, medical marijuana, cannabis and alternative cancer treatments then other terms were used as the data was gathered, particularly to research the databases with the names of people and organisations mentioned as articles were found and to update legislative changes. 
All relevant articles were summarised and ordered in a timeline, with the summaries identifying all players or spokespeople in the debate and the positions they took. The dataset focuses on media representations and so is limited by the particular framings of the media and the stories and spokespeople that the media selected. Other forms of research could uncover further framings and representations, such as research based on interviews with relevant players and that could draw on their networks. However, from this initial description based on media sources the underground status of medical marijuana was very clear and the theoretical concepts of hybridity and subalternity were used to shed light on the dynamics of the medical marijuana debate.

\section{The Story Unfolds}

The illegal status of marijuana was an issue that faced people who wanted to use it for medical purposes. In the popular imaginary the distribution of marijuana may be associated with criminals, gangs and drug dealers. A new kind of supplier developed to distribute marijuana for medical use that provided some rhetorical distance from these popular negative associations - the green fairies. Green fairies are those who provide marijuana for therapeutic, not recreational, purposes. This can be contrasted with the term 'dealer', given to those who provide marijuana for non-medical clients. One of these green fairies was Rose Renton, Alex Renton's mother, who continued to fight for medical access to marijuana and act as a proponent of marijuana reform after the death of her son. She was prosecuted in 2017 for the possession and growing of marijuana in her role as a green fairy for her Nelson community (Scoop, 2017b). Rose Renton appears in the media many times throughout $2015-17$ as a 
proponent of marijuana reform and critic of the government's inaction. In October 2016, she delivered a 17,000 signature petition to parliament calling for the legalisation of medical marijuana (Bay of Plenty Times, 2016).

In October 2015, Helen Kelly, then President of the Council of Trade Unions, revealed that she had been accessing cannabis illegally to self-medicate for pain while undergoing chemotherapy treatment for cancer (Moir, 2015b). This was taken up as a personal crusade to highlight the injustice of a lack of access to cannabis through legal means, a situation further clarified when Kelly tried and failed to gain access through an application to Peter Dunne and the MOH in January 2016 (Moir, 2016a). Kelly also promoted calls for a referendum on access to medical cannabis (Forbes, 2016). This advocacy was subsequently extended through her support of the group Medical Cannabis Awareness New Zealand (MCANZ) (Dominion Post, 2016). MCANZ was established in April 2016 by Shane Le Brun to provide financial and other support for patients seeking access to the cannabis plant. Le Brun provided a conservative take (Vine, 2016a) on access to medical cannabis, counter to what he saw as bandwagoning from recreational cannabis users who gave the movement a bad name (Vine, 2016b). Kelly died on October 14, 2016, with her cannabis advocacy mentioned in obituaries around the country (Macdonald, 2016).

Rose Renton and Helen Kelly were actively engaged with subaltern therapeutic practices of distribution and consumption. Access to medical cannabis could also be obtained through statist medicine, but at quite a price. The same month Helen Kelly spoke of her illegal use of cannabis, Zoe Jeffries became one of the youngest patients in New Zealand to be approved by the $\mathrm{MOH}$ for Sativex, a cannabis-based 
drug used in the treatment of epilepsy. The prohibitive cost of the drug was highlighted as Jeffries' family paid for the first script with a "well timed tax return" and turned to crowdfunding to fund the repeats (Wynn, 2015). While PHARMAC, the agency responsible for approving publicly subsidised medicines, considered funding Sativex in a July 2015 review (Nelson Mail, 2015), it was declined due to limited proof of efficacy in trials and on the basis of its potential for abuse. Abuse was argued to stem from the inherent nature of its active substances and the ease with which it can be administered (Norton, 2015). It is unclear how these arguments are differentiated from those for widely available pharmaceuticals such as opiate derivatives. Early articles on Jeffries noted that while there had been 97 ministerial approvals, there were only 27 current users (Wynn, 2015), a disparity at least in part explained by the difficulty faced by potential users in funding the drug.

In October 2016, Huhana Hickey became the first patient in New Zealand to have the cannabis based medicine Tilray approved for use (Hoyle, 2016). This would save her around $\$ 700$ a month due to the cheaper cost compared with her current drug Sativex (Vine, 2016c). She was compelled to stay with the legal options for fear of losing her job at the University of Auckland and to control the quality, side effects and consistency of her treatment despite the cost, which would have been greatly reduced if she were to source the raw plant material through the black market. A year later, Helen Old became one of the first patients in New Zealand to be approved for multiple different varieties of medical cannabis (Keith, 2017). Old suffered from multiple sclerosis and required more potent forms of medicinal cannabis at night and less potent forms during the day. She discovered the therapeutic effects of cannabis for her after participating in an illegal trial. The legal cannabis products would be 
sourced from Canada, and although she had got through the arduous year-long process of gaining legal approval with the support of her husband, her pain specialist and MCANZ, she still had to go through the process and cover the costs of obtaining an import license as well as pay for the drug. In contrast, Anna Osborne, who has been battling cancer since around the time of her husband's death in the Pike River mine disaster (Carroll, 2016), self-medicated with cannabis oil to treat pain after failed chemotherapy and to fight the ongoing symptoms of muscular dystrophy. She refused to seek access through legal channels due to the arduous process and prohibitive cost, given that she was already experiencing positive results in her selfmedication with black market cannabis (Plumb, 2016). These cases illustrate some of the barriers to access and contradictions of the current legal regime from a harm minimisation perspective, with cases of ill people compelled to access unregulated product on the black market.

In response to concerns like these Peter Dunne sought a review of the $\mathrm{MOH}$ guidelines for approving cannabis based medicines (Scoop, 2016a). The guidelines were established in the wake of Alex Renton's application to use Elixinol and this was an opportunity to fine tune them. The review disappointed advocates when it was completed in May 2016 with no recommended changes. Helen Kelly and Rose Renton were among a group who wrote an open letter condemning this investigation and calling for an independent review (Redmond, 2016). The open letter cited a biased methodology, misleading and deceptive scientific claims and a failure to promote patient rights. It was argued that the report failed to take into account the ways in which marijuana was being used with doctor discretion overseas and, instead, the review considered cannabis solely as a pharmaceutical product within 
the current Medicines Act. In an attempt to mitigate the situation, opposition Labour MP Damien O'Connor entered a bill into the ballot which would remove the $\mathrm{MOH}$ from the application process, allowing specialists to prescribe to patients who are in the final stages of a terminal illness, or have a permanent condition that causes significant pain or impairment (Redmond \& Moir, 2016). In November 2018 it was announced that a medical cannabis bill would be extended to cover palliative care. However, without PHARMAC funding or change to the Medsafe regime which restricts importation of cannabis products, this would do little to change the lack of uptake of medical marijuana in statist medicine (Dawson, 2016). Medsafe, the New Zealand Medicines and Medical Devices Safety Authority, is a business unit of the Ministry of Health responsible for overseeing drug safety activities.

Therapeutic practices in other jurisdictions had the potential to undermine statist medicine's control of the prescription of medical cannabis in Aotearoa New Zealand. In March 2016, Rebecca Reider received a discharge without conviction for the importation of cannabis medication from her birthplace, California. This revealed that there was a potential loophole in the law around importation of medications prescribed in other countries (Scoop, 2016b). This loophole was confirmed and the law as it currently stood admitted the possibility of bringing controlled drugs into the country if they had been legally prescribed (Hindmarsh, 2016a). Later that year Reider successfully brought a jar of raw cannabis, fully disclosed, through customs using her prescription from California (Jones, 2016a). However, the government reacted to this with an updated stance on importation from the US, no longer allowing controlled drug imports if they lacked US Food and Drug Administration approval (Hindmarsh, 2016b). This put New Zealand in the strange position of 
undermining Californian state law to uphold federal law that the US government was not imposing.

Cannabis products without psychoactive effects were also initially a target for law enforcement. Pearl Schomburg used cannabidiol (CBD) to replace a 'cocktail' of pharmaceutical drugs to manage her pain, although she could only access CBD illegally. She mounted a legal challenge to the government in 2017 to reclassify CBD products which were being incorrectly and potentially illegally caught under the Misuse of Drugs Act, classified as Class B1 controlled drugs in spite of their lack of psychoactive effect (Hoyle, 2017). Schomburg's challenge was responded to in mid2017, with CBD applications no longer requiring $\mathrm{MOH}$ approval and the drug instead being available for prescription by doctors in a similar manner to any other prescription medicine (Stuff, 2017). CBD was removed from the Misuse of Drugs Act after Dunne acted on advice from the Expert Advisory Committee on Drugs that CBD should not be a controlled drug as it has little or no psychoactive properties.

The approval system for cannabis-based medications became more liberal over the time period of the study. Initially Ministerial approval for these medications was required, then specialists and General Practitioners could prescribe those medications. But they could only prescribe cannabidiol products and cannot prescribe the raw plant.

Schomburg formed the Auckland Patients Group which, like the green fairies, helped patients struggling within the legal channels to gain access to black market cannabis (Scoop, 2017a). Schomburg was interviewed in November 2017 in relation to her 
Auckland Patients Group advocacy about the arrest of a prominent West Coast green fairy whose cannabis she had helped many patients gain access to (Press, 2017). His arrest would leave many patients struggling without access to their medication. The magazine New Zealand Doctor brought attention to this issue when it reported on a conference in which doctors spoke of the need to stop sending patients to drug dealers by restricting access to medicinal cannabis (Thomas, 2017). An Australian GP speaking at the conference claimed that $60 \%$ of cancer patients would be using cannabis illegally. The shift from Ministerial to $\mathrm{MOH}$ approval for cannabis based medicine applications in the February 2017 law change brought about by Peter Dunne (Live News, 2017) and the removal of CBD from the Misuse of Drugs Act, apparently had little effect on the realities of the medical cannabis marketplace (Fowlie, 2017).

Debates about medical marijuana tied in to debates over the decriminalisation or legalisation of the recreational use of marijuana as well as a possible cash crop that could benefit the economy. In 2016, it was revealed that the New Zealand Police had publicised and relied upon falsely reported data from a 2007 National Drug Intelligence Bureau (NDIB) report into the harms of cannabis (Wall, 2016b). An investigation by private citizen, Steve Dawson, uncovered that the report had exaggerated these harms ten-fold and wrongly cited cannabis as the leading source of drug harm in the country. The police claimed never to have used the report for operational purposes and refused to retract it given it was more than six years since its initial release. It was also discovered that the NDIB had already ignored a request for recall of the report from the $\mathrm{MOH}$ as far back as 2008 (Wall, 2016a). The police had used the report to contribute to a discourse in which harms of the cannabis plant 
were exaggerated, calling for further intensification of policing and resources. The misinformation about a new powerful cannabis and ballooning healthcare costs spread in articles following the initial release of the report in 2007 was never remedied (Easton, 2008). Neither the police nor NDIB were held to account for ignoring $\mathrm{MOH}$ advice and for the ensuing panic which led to calls such as urgent action on drug education in primary schools.

By contrast, economic arguments on the potential benefit of cannabis began to make headlines in 2016 as academics, politicians, business owners and farmers, among others, contributed to articles on the topic (McCarthy, 2016; Meadows, 2016a, 2016b; Mitchell, 2016; Sellman, 2016). Cannabis was considered as a potential crop for diversifying agriculture yields and increasing New Zealand's overall export profitability. The country was considered to have an optimal growing environment with farmers already operating in similar industries. A Drug Harm Index report commissioned by the $\mathrm{MOH}$ argued that taxing cannabis and reducing the spend on enforcement would increase overall revenue and reduce social harm (Jones, 2016b). A few months later, after an Official Information Act request from Sue Grey, who represented Rebecca Reider in her defence against cannabis importation charges, Treasury released internal documents showing a review had been carried out and circulated with claims of a huge tax windfall and enforcement savings (Moir \& Redmond, 2016). In August 2016, polls were released showing a mandate for cannabis reform from the public (Jones, 2016d). In spite of two thirds of New Zealanders showing support for some kind of reform, then Prime Minister John Key made unequivocal statements that change would not be forthcoming and reasserted his position that it would send the wrong message to young people (Jones, 2016c). 


\section{Conclusion}

The unfolding of the debate over medical marijuana in the media brings into sharp relief the existence of subaltern therapeutic forms. The dispositive of the medical and legal complexes limit the public life of subaltern forms. The positioning of the medical profession and statist medicine in the face of subaltern therapeutic practices, the latter aligning with notions of patient empowerment and patient-centred care, was to reinforce the channels of standard assessment, eschewing any engagement with something like 'whole herb' therapeutics, and working through MedSafe and the $\mathrm{MOH}$ to reassert biomedical hegemony. The $\mathrm{MOH}$ guidelines for approving cannabis-based medicines review of 2016 , and the extension of medical cannabis to palliative care without legalising the activities of green fairies and others, failed to provide any redress to a situation in which many patients accessed cannabis illegally to treat their conditions.

The appearance of subaltern therapeutic practices is then but a brief one as it sinks back down below the threshold of the public gaze, to continue unseen forms of resistance. The unruly hybrid of medical marijuana has been, in practice, purified once again into the different and separate spaces of statist medicine and subaltern therapeutics. In the subaltern world the production, distribution and consumption of therapeutic marijuana continues, with information shared in undocumented forms, dosages and procedures prescribed by unregulated 'therapists', and consumption based on trust and not official forms of credibility and status. In statist medicine bureaucratic processes prevail but leave in tact the control of the standardised form 
of therapeutic practice in medical hands. This is not to say, however, that standardised forms in medical hands eradicates the hybrid nature of medical marijuana as an oxymoron. In clinical practice where medical cannabis is an available option there remain difficulties for clinicians to distinguish recreational use from medical use, and for some clinicians the lack of scientific evidence for its efficacy remains an obstacle to prescription even in environments where it is legally available (Zolotov, Vulfsons, Zarhin, \& Sznitman, 2018). Clinicians in different specialities are more or less willing to prescribe it, for example, palliative care physicians being more open to prescribing a medication that is potentially addictive, drawing on their own observations and patient testimonials rather than relying on the science (Zolotov et al., 2018). In the subaltern realm efforts to standardise potencies and experiment with different cannabis varieties occurs, drawing on the science rhetoric of Statist medicine (Klein \& Potter, 2018).

The situation of the subaltern therapeutics of medical marijuana plays out in this particular way in Aotearoa New Zealand because of the status of marijuana as a criminalised object. If marijuana is legalised or decriminalised, then the subaltern practices of medical marijuana are likely to change. Some potential players in the debate about medical marijuana were noticeably absent in media representations. Although some people in the debate claimed that medical cannabis should be used as a whole herb - there was little in the way of the voices of herbalists, naturopaths or others practicing alternative health approaches. These practitioners sit somewhere between Statist medicine and subaltern medicine, with some alternative therapists like chiropractors and osteopaths having regulatory recognition and state support through such things as state subsidies of student education, and others 
unregulated and without state support but operating openly (Dew, 2003). If marijuana is legalised for recreational use, an issue that will be considered in a referendum on personal cannabis use that will be held in 2020 , it is possible that health practitioners working outside of biomedicine, generically labelled practitioners of complementary and alternative medicine (CAM), may take on a more public role in advocating for the use of medical marijuana in ways that defy biomedical prescriptions. Or it is possible that statist medicine will maintain its hegemonic position by proscribing the claims that can be made about medical marijuana so that any claims align with the outcomes of the formal regulatory processes of statist medicine - such as approval by the US Food and Drug Administration and approval by MedSafe in Aotearoa New Zealand.

Another prominent set of actors in this therapeutic tussle are those who may profit from the legal production and distribution of cannabis products. Statist medicine can potentially be undermined by private interests pursuing profit, which in turn can benefit the state in terms of tax revenues and a potential reduction in the importation of pharmaceuticals that medicinal cannabis would compete with. The economic interests of the state may then provide a source of credibility and legitimacy for cannabis without going through the hoops of statist medicine's regulatory systems. An analogous situation occurred in China in relation to Tibetan medicine. In China, market reforms introduced in the post-Mao period impacted upon the provision of Tibetan medicine. Tibetan medical practices could be provided at low cost, with many medications produced from locally available materials. The evaluation of Tibetan medicine within the confines of statist medicine's regulatory frameworks was replaced by an assessment of Tibetan medicine based on its capacity to support 
economic development goals (Janes, 2002). The same logic has the potential to play out in Aotearoa New Zealand if economic and patient interest groups could successfully combine forces.

Embedding medical marijuana into statist medicine would place economic as well as therapeutic constraints around its use. It would require isolated compounds of the cannabis plant being tested for safety and efficacy through the expensive process of randomised controlled trials, a process that requires capital investment (Yusuf et al., 2008). Subaltern economics is undertaken on a smaller scale, with producers and distributors not having such major capital outlay, and so enabling access to the plant and its products at a much lower price. But in the subaltern space the state does not provide any funding, whereas in statist medicine the possibilities of subsidies through PHARMAC have the potential to enable wider access.

The debates around medical marijuana may be unique as part of its subaltern positioning is a result of the illegal status of the plant as a drug of abuse. Information exchanges occur in informal ways, through such mechanisms as cannabis clubs (Klein \& Potter, 2018). But where claims about therapeutic outcomes are proscribed by statist medicine there are likely to be other forms of subaltern therapeutics. For example, proscribing what people can claim about a therapeutic practice may lead to the formation of information sharing practices that evade the gaze of the state - such as the use of closed or invitation only sites on social media. So, although the subaltern status of marijuana therapeutics is specific, its existence alerts us to the possibilities of other subaltern therapeutic practices. 


\section{References}

Bay of Plenty Times. (2016, 10/13). Plea for medicinal cannabis. Bay of Plenty Times. Retrieved from https://www.knowledge-basket.co.nz/databases/newztext/searchnewztext/view/?sid=1769098\&d26=nzh02\%2Ftext\%2F2016\%2F10\%2F13\%2FBTGDDn-MomentumGrowing13.html

Ben-Shabat, S., Fride, E., Sheskin, T., Tamiri, T., Rhee, M.-H., Vogel, Z., . . Mechoulam, R. (1998). An entourage effect: inactive endogenous fatty acid glycerol esters enhance 2-arachidonoyl-glycerol cannabinoid activity. European Journal of Pharmacology, 353(1), 23-31. doi:10.1016/S0014-2999(98)00392-6

Bennett, C. (2018). Drugs, moral panics and the dispositive. Journal of Sociology, 54(4), 538-556.

Blok, A., \& Jensen, T. (2011). Bruno Latour: Hybrid Thoughts in a Hybrid World. London and New York: Routledge.

Carroll, J. (2016, 04/18). Pike widow defiant over cannabis oil use. The Press. Retrieved from https://www.knowledge-basket.co.nz/databases/newztext-uni/searchnewztext/view/?sid=1769654\&d6=fairfax\%2Ftext\%2F2016\%2F04\%2F18\%2FA00311 14333959-AT.html

Cooke, H. $(2015,06 / 01)$. Desperate quest to save son, News. The Press, p. 1. Retrieved from https://www.knowledge-basket.co.nz/databases/newztext/searchnewztext/view/?sid=1767051\&d1=fairfax\%2Ftext\%2F2015\%2F06\%2F01\%2FA00211 02089457-AK.html

Darder, A., \& Griffiths, T. G. (2018). Revisiting "Can the subaltern speak?": introduction. Qualitative Research Journal, 18(2), 82-88. doi:10.1108/QRJ-D-17-00059

Dawson, K. (2016, 04/09). Man relies on cannabis for relief of chronic pain. Bay of Plenty Times. Retrieved from https://www.knowledgebasket.co.nz/databases/newztext/searchnewztext/view/?sid=1774612\&d6=nzh02\%2Ftext\%2F2016\%2F04\%2F09\%2FBTG09cannabis.html

Dew, K. (2003). Borderland practices: Regulating alternative therapies in New Zealand. Dunedin: University of Otago Press.

Dominion Post. (2016, 05/10). Kelly backs charity. The Dominion Post. Retrieved from https://www.knowledge-basket.co.nz/databases/newztext/searchnewztext/view/?sid=17774444\&d54=fairfax\%2Ftext\%2F2016\%2F05\%2F10\%2FA0031 115151318-AP.html

Easton, P. (2008, 12/27). They Say. The Dominion Post. Retrieved from https://www.knowledge-basket.co.nz/databases/newztext/searchnewztext/view/?sid=1782547\&d24=fairfax\%2Ftext\%2F2009\%2F01\%2F23\%2Fdoc00 052.html

Elsohly, M. A., Mehmedic, Z., Foster, S., Gon, C., Chandra, S., \& Church, J. C. (2016). Changes in Cannabis Potency Over the Last 2 Decades (1995-2014): Analysis of Current Data in the United States. Biological Psychiatry, 79(7), 613-619. doi:10.1016/j.biopsych.2016.01.004

Forbes, M. (2016, 01/09). Helen Kelly wants referendum on legalising cannabis at the next election. Stuff. Retrieved from http://www.stuff.co.nz/national/politics/75747087/Helen-Kelly-wants-referendum-onlegalising-cannabis-at-the-next-election

Fowlie, C. (2017, 06/05). Peter Dunne's new position on cannabis is meaningless, Opinion. The Daily Blog. Retrieved from https://www.knowledgebasket.co.nz/databases/newztext/search- 
newztext/view/?sid=1773384\&d43=blogs $\% 2 F$ text $\% 2 F$ dailyblog $\% 2 F 2017 \% 2 F 06 \% 2 F$ 05\%2F87464.html

Freidson, E. (1970). Profession of medicine; a study of the sociology of applied knowledge. New York: Dodd, Mead.

Grinspoon, P. (2018). Cannabidiol (CBD) - what we know and what we don't. Harvard Health Blog, https://www.health.harvard.edu/blog/cannabidiol-cbd-what-we-know-and-whatwe-dont-2018082414476.

Hardiman, D., \& Mukharji, P. B. (Eds.). (2012). Medical marginality in South Asia: situating subaltern therapeutics. London and New York: Routledge.

Hindmarsh, N. (2016a, 03/28). Cannabis 'loophole' confirmed. The Nelson Mail. Retrieved from https://www.knowledge-basket.co.nz/databases/newztext-uni/searchnewztext/view/?sid=1771833\&d168=fairfax\%2Ftext\%2F2016\%2F03\%2F28\%2F0001 1113593086-AB.html

Hindmarsh, N. (2016b, 12/10). Medicinal cannabis loophole closed. The Nelson Mail. Retrieved from https://www.knowledge-basket.co.nz/databases/newztext/searchnewztext/view/?sid=1769098\&d28=fairfax\%2Ftext\%2F2016\%2F12\%2F10\%2F00011 123214921-AC.html

Hoyle, C. (2016,11/13). First Kiwi approved for new cheaper medicinal cannabis treatment. Stuff. Retrieved from https://www.knowledgebasket.co.nz/databases/newztext/searchnewztext/view/?sid=1768664\&d99=ffxstuff $\% 2 F t e x t \% 2 F 2016 \% 2 F 11 \% 2 F 13 \% 2 F 0070$ 86224916.html

Hoyle, C. $(2017,01 / 22)$. Great-grandmother battles Ministry of Health over medicinal cannabis products. Sunday Star-Times. Retrieved from https://www.knowledgebasket.co.nz/databases/newztext-uni/searchnewztext/view/?sid=1769903\&d2=ffxstuff\%2Ftext\%2F2017\%2F01\%2F22\%2F009188635818.html

Janes, C. (2002). Buddhism, science, and market: the globalisation of Tibetan medicine. Anthropology and Medicine, 9(3), 267-289.

Jones, N. (2016a, 08/22). Customs lets cannabis into country. NZ Herald. Retrieved from https://www.knowledge-basket.co.nz/databases/newztext/searchnewztext/view/?sid=1769098\&d11=nzh02\%2Ftext\%2F2016\%2F08\%2F22\%2FNZHcannabis22.html

Jones, $\mathrm{N}$. (2016b, 04/09). Illicit drug trade worth $\$ 245 \mathrm{~m}$ in tax, social harm study suggests. NZ Herald. Retrieved from https://www.knowledge-basket.co.nz/databases/newztextuni/search-

newztext/view/?sid=1771892\&d15=nzh02\%2Ftext\%2F2016\%2F04\%2F09\%2FNZHdrugs09.html

Jones, N. (2016c, 08/16). Key says he's against drug change. NZ Herald. Retrieved from https://www.knowledge-basket.co.nz/databases/newztext-uni/searchnewztext/view/?sid=1769735\&d43=nzh02\%2Ftext\%2F2016\%2F08\%2F16\%2FNZHdecrim16.html

Jones, N. (2016d, 08/15). 'Legalise it' Exclusive Let us toke, say almost two-thirds of Kiwis in new poll. NZ Herald. Retrieved from https://www.knowledgebasket.co.nz/databases/newztext-uni/searchnewztext/view/?sid=1769735\&d42=nzh02\%2Ftext\%2F2016\%2F08\%2F15\%2FNZHcannabis15.html

Keith, L. (2017, 10/13). Woman wins approval for cannabis use. Taranaki Daily News. Retrieved from https://www.knowledge-basket.co.nz/databases/newztext/searchnewztext/view/?sid=1776174\&d46=fairfax\%2Ftext\%2F2017\%2F10\%2F13\%2F00011 134147752-AC.html

Kilmer, B., \& MacCoun, R. (2017). How medical marijuana smoothed the transition to marijuana legalization in the United States. Annual Review of Law and Social Science, 13, 181-202. 
Klein, A., \& Potter, G. (2018). The three betrayals of the medical cannabis growing activist: From multiple victimhood to reconstruction, redemption and activism. The International Journal on Drug Policy, 53, 65.

Larkin, G. (1983). Occupational monopoly and modern medicine. London: Tavistock Press.

Live News. (2017, 02/08). Ministry of Health to Decide on Cannabis-based Products, Release. Live News. Retrieved from https://www.knowledgebasket.co.nz/databases/newztext/searchnewztext/view/?sid=1772928\&d10=blogs $\% 2 F t e x t \% 2 F l i v e n e w s \% 2 F 2017 \% 2 F 02 \% 2 F 0$ 8\%2Fministry-of-health-to-decide-on-cannabis-based-products.html

Macdonald, N. (2016, 10/15). Fearless fighter loses her biggest battle. Manawatu Standard. Retrieved from https://www.knowledge-basket.co.nz/databases/newztext/searchnewztext/view/?sid=1768664\&d86=fairfax\%2Ftext\%2F2016\%2F10\%2F15\%2F00041 121174051-AP.html

McCarthy, P. (2016, 04/28). Medical cannabis issue needs debate, Opinion. Taranaki Daily News. Retrieved from https://www.knowledgebasket.co.nz/databases/newztext/searchnewztext/view/?sid=1777444\&d51=fairfax\%2Ftext\%2F2016\%2F04\%2F28\%2FA0141 114705578-Cl.html

Meadows, R. (2016a, 04/17). Cashing in. Sunday Star-Times. Retrieved from https://www.knowledge-basket.co.nz/databases/newztext-uni/searchnewztext/view/?sid=1771892\&d24=fairfax\%2Ftext\%2F2016\%2F04\%2F17\%2FD0061 114266033-FL.html

Meadows, R. (2016b, 04/17). War on drugs an 'abject failure' yet legal cannabis remains a pipe dream. Sunday Star-Times. Retrieved from https://www.knowledgebasket.co.nz/databases/newztext/searchnewztext/view/?sid=1775247\&d61=fairfax\%2Ftext\%2F2016\%2F04\%2F17\%2FA0091 114269239-BD.html

Mitchell, C. (2016, 04/25). NZ missing the boat on cannabis - scientist. The Press. Retrieved from https://www.knowledge-basket.co.nz/databases/newztext/searchnewztext/view/?sid=1774557\&d8=fairfax\%2Ftext\%2F2016\%2F04\%2F $25 \% 2 F A 00311$ 14612466-AU.html

Moir, J. (2015a, 06/08). Delay 'borders on unethical'. The Press. Retrieved from https://www.knowledge-basket.co.nz/databases/newztext/searchnewztext/view/?sid=1767051\&d14=fairfax\%2Ftext\%2F2015\%2F06\%2F08\%2FA0021 102358742-AL.html

Moir, J. (2015b, 10/13). Helen Kelly says Government needs to get real about medicinal cannabis. Stuff. Retrieved from https://www.knowledgebasket.co.nz/databases/newztext-uni/searchnewztext/view/?sid=1771085\&d30=ffxstuff\%2Ftext\%2F2015\%2F10\%2F13\%2F004972923212.html

Moir, J. (2015c, 06/10). One-off medicinal cannabis approved. The Dominion Post. Retrieved from https://www.knowledge-basket.co.nz/databases/newztext/searchnewztext/view/?sid=1767051\&d25=fairfax\%2Ftext\%2F2015\%2F06\%2F10\%2FA0031 102429841-AV.html

Moir, J. (2016a, 02/16). Defying the odds on cancer. The Dominion Post. Retrieved from https://www.knowledge-basket.co.nz/databases/newztext-uni/searchnewztext/view/?sid=1771085\&d112=fairfax\%2Ftext $\% 2 F 2016 \% 2 F 02 \% 2 F 16 \% 2 F A 002$ 1111966245-AG.html

Moir, J. (2016b, 01/19). Medicinal cannabis did help my son, says mother. The Dominion Post. Retrieved from https://www.knowledge-basket.co.nz/databases/newztextuni/searchnewztext/view/?sid=1771085\&d90=fairfax $\% 2 F t e x t \% 2 F 2016 \% 2 F 01 \% 2 F 19 \% 2 F A 0021$ 110924343-AF.html

Moir, J., \& Redmond, A. (2016, 07/21). Big money in cannabis for Govt. The Press. Retrieved from https://www.knowledge-basket.co.nz/databases/newztext/search- 
newztext/view/?sid=1772784\&d1=fairfax\%2Ftext\%2F2016\%2F07\%2F21\%2FA00211 17969050-AD.html

Morton, A. D. (2007). Unravelling Gramsci: Hegemony and Passive Revolution in the Global Political Economy. London: Pluto Press.

Nelson Mail. (2015, 07/28). Spray funding seen as a step forward. The Nelson Mail. Retrieved from https://www.knowledge-basket.co.nz/databases/newztext/searchnewztext/view/?sid=1776290\&d51=fairfax\%2Ftext\%2F2015\%2F07\%2F28\%2F00081 104342927-BY.html

Norton, M. (2015). Pharmac bid to fund medical cannabis shut down by clinical advisors. In New Zealand Doctor: More than medicine. Auckland: The Health Media.

Pedersen, W., \& Sandberg, S. (2013). The medicalisation of revolt: a sociological analysis of medical cannabis users. Sociology of Health \& IIIness, 35(1), 17-32.

Plumb, S. (2016, 04/02). No headline: leadcannabis. NZ Herald. Retrieved from https://www.knowledge-basket.co.nz/databases/newztext/searchnewztext/view/?sid=1768664\&d43=nzh02\%2Ftext\%2F2016\%2F04\%2F02\%2FNZHleadcannabis.html

Press. (2017). Panic after posties dob in supplier of medical cannabis. The Press, pp. Retrieved from https://www.knowledge-basket.co.nz/databases/newztext-uni/searchnewztext/view/?sid=1769896\&d1769894=fairfax\%1769892Ftext\%1769892F1762017 \%1769892F1769811\%1769892F1769804\%1769892FA0161134818423-BL.html

Redmond, A. (2016, 06/07). Medicinal cannabis review 'ignorant'. The Nelson Mail. Retrieved from https://www.knowledge-basket.co.nz/databases/newztext-uni/searchnewztext/view/?sid=1771997\&d20=fairfax\%2Ftext\%2F2016\%2F06\%2F07\%2F00011 116284462-AC.html

Redmond, A., \& Moir, J. (2016, 04/09). Rose Renton backs 'brave' cannabis bill. Nelson Mail. Retrieved from https://www.knowledge-basket.co.nz/databases/newztextuni/search-

newztext/view/?sid=1769735\&d25=fairfax\%2Ftext\%2F2016\%2F04\%2F09\%2F00031 114003331-AM.html

Scoop. (2016a, 02/26). Dunne requests further consideration of medical cannabis. Scoop. Retrieved from https://www.knowledge-basket.co.nz/databases/newztext-uni/searchnewztext/view/?sid=1771085\&d116=scoop \%2Ftext\%2F2016\%2F02\%2F26\%2FPA16 02-S00391.html

Scoop. (2016b, 03/04). Possible Loophole for Medical Cannabis Importation. Scoop. Retrieved from https://www.knowledge-basket.co.nz/databases/newztext/searchnewztext/view/?sid=1774792\&d2=scoop $\% 2$ Ftext $\% 2 F 2016 \% 2 F 03 \% 2 F 04 \% 2 F P O 160$ 3-S00067.html

Scoop. (2017a, 10/11). "Green Fairies" Are a Symptom of Unmet Demand. Scoop. Retrieved from https://www.knowledge-basket.co.nz/databases/newztext/searchnewztext/view/?sid=1776174\&d45=scoop\%2Ftext\%2F2017\%2F10\%2F11\%2FGE17 10-S00059.html

Scoop. (2017b, 10/17). Well-Known Nelson Green Fairy Faces Prosecution. Scoop. Retrieved from https://www.knowledge-basket.co.nz/databases/newztext/searchnewztext/view/?sid=1774806\&d55=scoop\%2Ftext\%2F2017\%2F10\%2F17\%2FGE17 10-S00079.html

Sellman, P. D. (2016, 04/12). Control of legalised cannabis best placed in govt hands, Opinion. NZ Herald. Retrieved from https://www.knowledgebasket.co.nz/databases/newztext-uni/searchnewztext/view/?sid=1771892\&d18=nzh02\%2Ftext\%2F2016\%2F04\%2F12\%2FNZHSellman12.html

Shi, Y., Liang, D., Bao, Y., An, R., Wallace, M. S., \& Grant, I. (2019). Recreational marijuana legalization and prescription opioids received by Medicaid enrollees. Drug and Alcohol Dependence, 194, 13-19. doi:10.1016/j.drugalcdep.2018.09.016 
Stuff. (2015a, 07/19). Cannabis oil given to Alex Renton before Government approval. Stuff. Retrieved from https://www.knowledge-basket.co.nz/databases/newztext/searchnewztext/view/?sid=1770815\&d86=ffxstuff\%2Ftext\%2F2015\%2F07\%2F20\%2F009870359880.html

Stuff. (2015b, 07/01). Nelson teenager Alex Renton dies. Stuff. Retrieved from https://www.knowledge-basket.co.nz/databases/newztext/searchnewztext/view/?sid=1770815\&d65=ffxstuff\%2Ftext\%2F2015\%2F07\%2F02\%2F017369888664.html

Stuff. $(2017,06 / 02)$. Kiwis will now be able to get medicinal cannabis from their doctor, Government announces. Stuff. Retrieved from https://www.knowledgebasket.co.nz/databases/newztext/searchnewztext/view/?sid=1773384\&d23=ffxstuff $\% 2 F t e x t \% 2 F 2017 \% 2 F 06 \% 2 F 02 \% 2 F 0031$ 93268869.html

Thomas, F. (2017, 07/05). Seeking access to medicinal cannabis: 'Don't send patients to drug dealers' New Zealand Doctor: More than Medicine.

Vine, P. (2016a, 09/24). Cry of mainstream pain: let us use marijuana. NZ Herald. Retrieved from https://www.knowledge-basket.co.nz/databases/newztext/searchnewztext/view/?sid=1768330\&d54=nzh02\%2Ftext\%2F2016\%2F09\%2F24\%2FNZHdope24.html

Vine, P. (2016b, 09/27). Dope reform group hits back at conservative cannabis lobbyists. NZ Herald. Retrieved from https://www.knowledge-

basket.co.nz/databases/newztext/searchnewztext/view/?sid=1772784\&d39=nzh02\%2Ftext $\% 2 F 2016 \% 2 F 09 \% 2 F 27 \% 2 F N Z H-$ stoners27.html

Vine, P. (2016c, 10/16). Fresh hope in legal battle over medical cannabis. Herald on Sunday. Retrieved from https://www.knowledgebasket.co.nz/databases/newztext/searchnewztext/view/?sid=1768330\&d51=nzh02\%2Ftext $\% 2 F 2016 \% 2 F 10 \% 2 F 16 \% 2 F N Z H-$ Wkdope16.html

Wade, S. P. A. $(2016,01 / 16)$. Medical cannabis worthwhile as a palliative but not a treatment, report suggests. NZ Herald. Retrieved from https://www.knowledgebasket.co.nz/databases/newztext-uni/searchnewztext/view/?sid=1771085\&d88=nzh02\%2Ftext\%2F2016\%2F01\%2F16\%2FNZHrenton16.html

Wall, T. (2016a, 04/24). Dope warnings ignored. Sunday Star Times. Retrieved from https://www.knowledge-basket.co.nz/databases/newztext/searchnewztext/view/?sid=1782534\&d2=fairfax\%2Ftext\%2F2016\%2F04\%2F24\%2FA00511 14582967-AY.html

Wall, T. (2016b, 04/17). How an unemployed Westie discredited a key police report on cannabis. Stuff. Retrieved from https://www.knowledgebasket.co.nz/databases/newztext-uni/searchnewztext/view/?sid=1771958\&d27=ffxstuff\%2Ftext\%2F2016\%2F04\%2F17\%2F001778486729.html

Willis, E. (1983). Medical dominance: the division of labour in Australian Healthcare. Sydney: George Allen \& Unwin.

Wynn, K. (2015, 10/18). Ministry approves cannabis treatment for 7-year-old girl. NZ Herald. Retrieved from https://www.knowledge-basket.co.nz/databases/newztext-uni/searchnewztext/view/?sid=1771085\&d40=nzh02\%2Ftext\%2F2015\%2F10\%2F18\%2FNZHkwzoe18.html

Yusuf, S., Bosch, J., Devereaux, P., Collins, R., Baigent, C., Granger, C., . . Temple, R. (2008). Sensible guidelines for the conduct of large randomized trials. Clinical Trials, 5(1), 38-39.

Zarhin, D., Negev, M., Vulfsons, S., \& Sznitman, S. R. (2018). Rhetorical and regulatory boundary-work: The case of medical cannabis policy-making in Israel. Social Science \& Medicine, 217, 1-9. doi:10.1016/j.socscimed.2018.09.047 
Zolotov, Y., Vulfsons, S., Zarhin, D., \& Sznitman, S. (2018). Medical cannabis: An oxymoron? Physicians' perceptions of medical cannabis. International Journal of Drug Policy, 57, 4-10. doi:10.1016/j.drugpo.2018.03.025 